\title{
UMA ANÁLISE LÓGICA DOS VOTOS DOS MINISTROS DO STF NO HC 91.952-9/SP SEGUNDO A TEORIA DA ARGUMENTAÇÃO JURÍDICA DE MANUEL ATIENZA
}

RESUMO: Este trabalho trata de uma análise lógica dos votos dos Ministros do Supremo Tribunal Federal, durante o julgamento do HC n. 91.952-9/SP, segundo o modelo da Argumentação Jurídica de Manuel Atienza. A decisão analizada deu origem a Súmula Vinculante $\mathrm{n}^{\mathrm{o}}$. 11, conhecida como Súmula das Algemas. A Teoria da Argumentação Jurídica de Atienza propõe um modelo de análise de decisões difíceis, para com isso, mapear através de um modelo gráfico o sentido e significado de uma decisão judicial. Pretende-se, assim, compreender a lógica da argumentação dos Ministros, verificando se o modelo proposto por Atieza se adequa a decisão tomada.

Palavras-Chave: Análise de Votos. Súmula Vinculante n. 11. Supremo Tribunal Federal. Teoria da Argumentação Jurídica.

\section{A LOGICAL ANALYSIS OF THE JUSTICES VOTES OF BRAZILIAN SUPREME COURT IN THE HC 91.952-9/SP IN ACCORD OF THEORY OF THE LEGAL ARGUMENTATION OF MANUEL ATIENZA}

ABSTRACT: This paper deals with a logical analysis of the votes of the Justices of the Brazilian Supreme Court during the HC n. 91.952-9/SP, according to the model of the Legal Argumentation of Manuel Atienza. The Theory of Legal Argumentation of Atienza proposes a model of analysis of difficult decisions or hard cases, with that, to map through a graphic model the meaning and meaning of a judicial decision. The aim is to understand the logic of the Ministers' argument, verifying whether the model proposed by Atieza is appropriate to the decision taken.

Keywords: Analysis of Votes; HC n. 91.952-9/SP; Brazilian Supreme Court; Theory of Legal Argumentation.

\section{INTRODUÇÃOO}

O Direito é categorizado como uma ciência humana aplicada, move-se com regras próprias, tem uma lógica própria, é uma matéria que usa da linguagem cientifica para

\footnotetext{
${ }^{1}$ Mestrando em Direito Constitucional pela Escola de Direito de Brasília (EDB/IDP). Professor de Direito Constitucional e Adminsitrativo. Graduado em Direito pelo Centro Universitário de Brasília (2014). Pesquisador em Direito do Instituto Brasiliense de Direito Público (IDP) desde 2011, atuando principalmente no tema: direitos fundamentais. Presidente/vogal de Comissões de Processo Administrativo Disciplinar (MEC), Corregedor Substituto do Ministério da Educação. Tem experiência na área de Direito Público, com ênfase em gestão e fiscalização de contratos, licitações e processo administrativo disciplinar.
}

Teorias de Direito e Realismo Jurídico | e-ISSN: 2525-9601| Brasília | v. $3 \mid$ n. 1 | p. 1 - 19 | Jan/Jun. 2017. 
alcançar seus objetivos, como também, se utiliza de recursos de várias outras áreas do conhecimento para através das normas regular a sociedade coercitivamente. Esse trabalho tenta investigar, através do estudo de um caso, a lógica de uma decisão judicial através da Teoria da Argumentação Jurídica de Atienza.

O estudo de caso que será analisado é o julgado do Supremo Tribunal Federal (STF) que deu origem a uma súmula vinculante $\mathrm{n}$. 11. O julgado a ser analisado será o Habeas Corpus (HC) n. 91.952-9/SP, conhecida como "Súmula das Algemas", ou ainda "Súmula Cacciola-Dantas". ${ }^{2}$ Será utilizado para análise dos votos, a Teoria da Argumentação Jurídica de Atienza, que tem por objeto verificar a coerência lógica argumentativa através do mapeamento de argumentos utilizados e representá-los em um modelo gráfico que se verifique o sentido e o significado da decisão tomada.

O motivo para a escolha da Súmula das Algemas se deu devido a ser esse considerado um caso difícil (hard case). Caracterizando assim, um caso difícil, como sendo um julgado complicado, que não tem uma solução rápida de acordo com o direito posto. Segundo Dworkin ${ }^{3}$ quando não existe uma lei regulado uma determinada situação, e com isso o julgador precisar procurar descobrir qual o direito das partes. Como a decisão no caso gerou a criação da Súmula Vinculante n.11, que de certa forma tem uma conotação de proteção da classe política contra as ações da polícia, tal caso gerou uma celeuma em 2008 nos meios de comunicação, no meio jurídico ${ }^{4}$ e legislativo. ${ }^{5}$

Esse tema surgiu a partir da preocupação por um sentido racional nas decisões jurídicas. Até certo ponto, uma busca pelo que é direito e justo nessas decisões que geram impacto na vida de milhares de pessoas. O interesse foi despertado pelos debates em sala de aula, grupos de estudo, onde discute-se a racionalidade das decisões tomadas no Supremo Tribunal Federal (STF) e os parâmetros utilizados nessas decisões.

O problema principal enfrentado nestas páginas será: pode os votos dos Ministros do Supremo Tribunal Federal no HC 91.952-9/SP serem encaixados no modelo da teoria da argumentação jurídica de Atienza, de modo a se verificar uma coerência argumentativa e lógica nos votos?

Para tanto, sustenta-se, hipoteticamente, que os votos dos Ministros obedeceram uma lógica deôntica e argumentativa, e que foi usado pesos e medidas proporcionais para decidir um tema controverso, em relação à omissão legislativa, interpretativa ou a efetividade sobre o uso regular das algemas.

O que irá se verificar com o estudo dos votos é a questão da possibilidade da adequação dos votos ao modelo proposto por Atienza. Com isso, efetuar-se-á uma análise dos votos dos Ministros do Supremo averiguando assim a racionalidade (logos) desses votos através da Teoria de Atienza. Com isso, poderá se confirmar se tais votos foram proferidos com base em precedentes legais já existentes na corte, legislação, jurisprudência, precedentes históricos, ou se existe alguma criação doutrinária à respeito do assunto. Na busca por esse

2 Macedo, Fausto. Juízes se rebelam contra súmula Cacciola-Dantas. O Estado de São Paulo. 16 ago. 2008. p. A16. Disponível em: <http://www2.senado.gov.br/bdsf/item/id/ 345034>. Acesso em: 24 maio 2014.

3 DWORKIN, Ronald. Levando os direitos a sério.Tradução de Nelson Boeiras. São Paulo: Martins Fontes, 2002. p.127.

4 O Procurador-Geral da República, Roberto Gurgel, encaminhou parecer ao Supremo Tribunal Federal (STF) opinando pelo cancelamento da Súmula Vinculante $\mathrm{n}^{\circ}$ 11, editada pelo STF em agosto de 2008 para evitar o uso abusivo de algemas. A edição da súmula foi questionada pela Confederação Brasileira dos Trabalhadores Policiais Civis (Cobrapol). Disponível em: <http://noticias.pgr.mpf.mp.br/noticias/noticias-do-site/ copy_of_criminal/pgr-defende-cancelamento-de-sumula-sobre-uso-de-algemas >. Acesso em 11 set. 2014. 
objetivo utiliza-se uma série de pensadores do Direito. Pode-se citar entre os principais Aristóteles, Neil McCormick, Robert Alexy e Atienza.

Existem algumas categorias teóricas serão desenvolvidas no decorrer do trabalho por se relacionarem com a argumentação jurídica, conceitos como: retórica, persuasão, persuasão e auditório. Esses conceitos serão investigados no decorrer desse trabalho e são se suma importância para a compreensão do assunto.

As partes desse artigo foram desenvolvidos da seguinte maneira, no item 1 é feita a introdução ao estudo, definindo a metodologia, hipótese e objetivos a serem alcaçados. No item 2 demonstra-se como a Teoria da Argumentação Jurídica de Atienza pode ser utilizada para a análise de casos difíceis. Entre outras questões desenvolve-se a definição de algumas categorias teóricas desse trabalho, alguns aspectos relacionados com o tema como: hermenêutica, persuasão, auditório e ainda um pequeno estudo sobre as falácias. Enquanto no item 3 faz-se uma exposição do caso concreto. Aprofunda-se a análise dos votos prolatados e suas respectivas fundamentações no julgamento do HC n. 91.952-9/SP, explicando toda a argumentação utilizada. Aplica-se o modelo gráfico da Teoria da Argumentação Jurídica de Atienza aos votos carreados no acórdão, para assim, conseguir extrair o sentido e o significado da decisão. Compõe-se o modelo gráfico dos votos segundo a Teoria de Atienza. Fragmenta-se cada um dos votos com o objetivo de entender todas os detalhes de cada voto dos Ministros do STF. Depois é feito uma remontagem desses votos graficamente segundo o modelo estudado. Por fim, no item 4 a conclusão aborda o que foi aprendido no decorrer do trabalho desenvolvido sobre argumentação jurídica. Verifica-se também se os votos dos Ministros do Supremo Tribunal Federal no HC 91.952-9/SP puderam ser adaptados ao modelo da Teoria da Argumentação Jurídica de Atienza. E em consequência se examina-se a questão sustentada. Se os votos dos Ministros obedeceram uma lógica deôntica e argumentativa, e se foi usado pesos e medidas adequadas com a lógica argumentativa para decidir um caso difícil.

\section{A TEORIA DE ATIENZA COMO MÉTODO PARA ANÁLISE DE CASOS DIFICÉIS}

É impossível visitar os escritos de todos os pensadores importantes sobre o assunto, mas dentre os principais pode-se eleger um grupo que corrobora melhor para a construção do trabalho e esses são: Aristóteles, Schopenhauer, Dworkin, Neil MacCormick, Habermas, Robert Alexy e Manuel Atienza. Claro que no decorrer da pesquisa podem ser acrescentados outros pensadores do assunto. Entre os autores nacionais que devem ser referenciados encontram-se Fábio Ulhôa Coelho (Pontifícia Universidade Católica de São Paulo), Claudia Roesler (Unb), Isaac Costa Reis(Unb) e Paulo Gustavo Gonet Branco (IDP). ${ }^{6}$

$\mathrm{O}$ primeiro pensador clássico a escrever à respeito da lógica foi Aristóteles em seu livro Organon. Aristóteles, nesse livro, divide a lógica em formal e material, essa última trata de organizar o pensamento, segundo a natureza dos objetos que se deseja conhecer e fazer adequação do raciocínio à realidade que se apresenta. A lógica material é a que mais se aproxima da construção do raciocínio jurídico, visto que, além das questões básicas de causa e consequência que tem que ser observadas no raciocínio jurídico, tem toda uma ocorrência de questões sociais de uma época que deve ser levada em consideração.

Fábio Ulhôa Coelho, discutindo a relação de lógica e direito, defende que o direito não é um sistema lógico,

Sistema é o resultado de uma relação específica estabelecida entre os elementos de seu repertório. Um sistema de ideias relacionadas entre si, com

\footnotetext{
${ }^{6}$ BRANCO, Paulo Gustavo Gonet. Juízo de ponderação na jurisdição constitucional. São Paulo: Saraiva, 2009.
}

Rev.de Teorias da Just., da Decisão e da Argumentação Jurídica l e-ISSN: $2525-9644$ | Brasília | v. 3 | n. 1 | p. $1-19$ | Jan/Jun. 2017. 
estrita observância dos princípios da identidade, da não-contradição e do terceiro excluído, é um sistema lógico. Para que o direito possa ser entendido como um sistema lógico, ele deve atender a essa condição. Contudo, a possibilidade de antinomias reais e de lacunas num conjunto sistemático de normas jurídicas caracteriza a desconsideração de princípio lógicos e inviabiliza, por isso, o empreendimento teórico de se tratar o direito sob o ponto de vista da lógica. Em suma, o sistema jurídico não é lógico. ${ }^{7}$

Segundo Ulhôa, para que o direito fosse lógico teria que ter uma estrita observância de princípios de identidade, que privaria ao sistema jurídico da contradição, mas como o direito permite a possibilidade da contradição e antinomias, esse passa a ser um sistema, não lógico.

Mas também não é aleatório. Os integrantes da comunidade jurídica não podem formular livremente a norma que desejarem em seu pensamento e pretende-la vigente. O sistema jurídico tem uma congruência, uma unidade. Se os elementos de seu repertório (as normas, as proposições, as súmulas etc.) não se encontram relacionados logicamente, com certeza eles mantêm uma relação de natureza diversa. Uma relação que, por outro lado, também não poderia ser considerada ilógica, porque se pretende lógica, se apresenta como tal. Assim, proponho que se considere de caráter pseudológico a congruência do sistema jurídico. Em suma, o sistema jurídico não é lógico, mas retórico." 8

Dessa forma, não se pode dizer que o sistema jurídico é lógico, mas também não é aleatório e portanto precisa, e tem alguma congruência. Essa congruência é construída pela contraposição de ideias, por isso entende o Fabio Ulhôa que o sistema jurídico é retórico e não lógico. E como um sistema retórico, é um sistema que permite o confronto de ideias, desse confronto de ideias que surge o direito. A lógica do sistema jurídico vem através justamente do embate retórico das ideias, para que se construa dessa forma uma decisão mais justa possível ou um sistema jurídico que promova o consenso. O consenso é um conceito que será resgatado mais a frente para entender-se como se dá na teoria de Alexy a construção do consenso e da força do melhor argumento.

Nesse mesmo sentido Atienza entende a lógica como um fator insuficiente para entender o sentido e significado da decisão judicial. "Foi a consciência - às vezes exagerada - dessa insuficiência da lógica que deu origem, a partir dos anos 50, ao que hoje entendemos como "teorias da argumentação jurídica". 9 "

A argumentação jurídica é um raciocínio encadeado de forma lógica a tentar resolver determinado problema jurídico que se apresenta ao operador do direito. Esse problema pode ser: um cliente preso, que esta sendo acusado de um crime; uma empresa que não recolheu um tributo de forma correta; um direito a privacidade que esta sendo violado, entre outros. A questão é que todo e qualquer direito que seja pleiteado em juízo tem que ter um mínimo de lógica argumentativa para aquele que vai apreciar o pedido, e o pedido tem que fazer sentido e suportar o contraditório.

Nesse contexto surgem diversas teorias que tentam explicar o que é a argumentação jurídica e suas diversas relações estabelecidas tanto dentro do direito como em outras ciências sociais.

${ }^{7}$ COELHO, Fábio Ulhôa. Roteiro de lógica jurídica. 5. ed. São Paulo: Saraiva, 2004. p. 87.

${ }^{8}$ COELHO, Fábio Ulhôa. Roteiro de lógica jurídica. 5. ed. São Paulo: Saraiva, 2004. p. 87.

9 ATIENZA, Manuel. As razões do direito: teorias da argumentação jurídica. 3. ed. São Paulo: Landy, 2003. p. 18-19.

Rev.de Teorias da Just., da Decisão e da Argumentação Jurídica l e-ISSN: $2525-9644$ | Brasília | v. 3|n. 1 | p. $1-19$ | Jan/Jun. 2017. 
Atienza define o obejto da teoria da argumentação jurídica como sendo as argumentações produzidas em um contexto jurídico. Além disso, define os três diferentes campos jurídicos que podem ser estudados através de seu modelo,

A teoria (ou teorias) da argumentação jurídica tem como objeto de reflexão, obviamente, as argumentações produzidas em contextos jurídicos. Em princípio pode-se distinguir três diferentes campos jurídicos em que podem ocorrer argumentações. O primeiro é o da produção ou estabelecimento de normas jurídicas. [...] Um segundo campo em que se efetuam argumentos jurídicos é o da aplicação de normas jurídicas à solução de casos, embora essa seja uma atividade levada a cabo por juízes em sentido estrito, por órgãos administrativos no sentido mais amplo da expressão ou por simples particulares. [...] Finalmente, o terceiro âmbito em que se verificam argumentos jurídicos é o da dogmática jurídica. A dogmática é, sem dúvida, uma atividade complexa, na qual cabe distinguir essencialmente as seguintes funções: 1) fornecer critérios para a produção do Direito nas diversas instâncias em que ele ocorre; 2) oferece critérios para a aplicação do Direito; 3) ordenar e sistematizar um setor do ordenamento jurídico.10

O que interessa para o contexto desse estudo, é justamente, o segundo campo que define a aplicação da norma jurídica à solução de casos, mais especificamente o caso estudado que acaba se enquadrando na questão de um Tribunal que decidiu uma questão de maneira geral e vinculante devido ao instrumento constitucional da Súmula Vinculante.

Além disso alguns tribunais, ao decidirem um caso concreto, criam jurisprudência, o que significa que a regra em que baseiam a sua decisão - e que se expressa na ratio deciendi da sentença - tem um caráter geral e abstrato, e consequentemente vale para os casos futuros. ${ }^{11}$

Atienza discute a relação entre a argumentação jurídica e lógica e mostra que os argumentos jurídicos podem-se ser vistos de várias maneiras diferentes e além da lógica, mas também de acordo com diferentes ciências,

Por um lado, se pode dizer que a argumentação jurídica vai além da lógica jurídica porque, como vimos anteriormente, os argumentos jurídicos podem ser estudados também de uma perspectiva que não é a da lógica: por exemplo da perspectiva psicológica ou sociológica, ou então da perspectiva não formal, às vezes chamada de "lógica material" ou "lógica informal", e outra vezes de "tópica", "retórica", "dialética" etc. Por outro lado, a lógica jurídica vai além da argumentação jurídica no sentido de que tem um objeto de estudo mais amplo. Para esclarecer isso podemos utilizar uma conhecida distinção feita por Bobbio(1965) dentro da lógica jurídica. Na sua opinião a lógica jurídica seria constituída pela lógica do Direito, que se concentra na análise da estrutura lógica dos juristas, que se ocupa do estudo dos diversos raciocínios ou argumentações feitos pelos juristas teóricos ou práticos.12

Diante disso tem-se diferentes tipos de problemas jurídicos que podem ser encontrados em uma determinada decisão, segundo MacCormick existem quatro tipos de problemas jurídicos: problemas de pertinência, interpretação, prova e qualificação.

10 ATIENZA, Manuel. As razões do direito: teorias da argumentação jurídica. 3. ed. São Paulo: Landy, 2003. p. 19.

11 Ibidem.

12 ATIENZA, Manuel. As razões do direito: teorias da argumentação jurídica. 3. ed. São Paulo: Landy, 2003. p. 40.

Rev. de Teorias da Just., da Decisão e da Argumentação Jurídica l e-ISSN: $2525-9644$ | Brasília|v. $3|\mathrm{n} .1| \mathrm{p} .1-19 \mid \mathrm{Jan} / \mathrm{Jun} .2017$. 
Entrando agora um pouco no contexto do caso que será analisado, verifica-se de forma clara que o problema jurídico qual se encara é uma questão de pertinência, haja visto que não se sabia ao certo qual norma seria aplicável ao caso. De todos os dispositivos legais visitados no voto do Ministro Relator Marco Aurélio o que mais se coaduna com a expectativa legal se encontra no Código de Processo Penal Militar, em seu art. 234 e 242, que não se aplica de imediato ao mundo civil, visto que, o público alvo de tal dispositivo são militares da ativa e da reserva de forma primordial.

Apesar de não ser a investigação primordial, é interessante observar que apesar de terem uma série de dispositivos legais que apontam para a proteção da dignidade da pessoa humana, punição para o uso abusivo de força pela autoridade, a questão de se evitar o uso das algemas, nunca havia sido observado esse modo de agir em território nacional. A questão é que em termos de política criminal todo Código Penal tem um público e com o advento da Lei de Improbidade Administrativa, Lei de Responsabilidade Fiscal, a elite brasileira como define Raimundo Faoro ${ }^{13}$, pode agora ser tocada pelas forças policiais.

Conjunto de normas podem ser de tal natureza que todas elas sejam compatíveis com alguma norma mais geral, podendo, portanto, ser consideradas como manifestações mais específicas ou "concretas" dessa norma. Se alguém considerar essa norma mais geral uma sólida e sensata, ou justa e desejável para a condução de relações, essa pessoa poderá com acerto tratar essa norma como um "princípio" que tanto explica como justifica todas as normas mais específicas em questão ou qualquer uma delas. Quanto a justificação: se alguma norma $\mathrm{n}$ for valorizada em si como um meio para um fim almejado, demonstrar que uma norma específica pode ser subordinada a ela corresponde a demonstrar que se trata de uma norma a seguir. Quanto à explicação: quando estamos em dúvida acerca do correto significado da norma num determinado contexto, uma consulta ao princípio pode nos ajudar a explicar como ela deve ser entendida; também, de modo superficial, é possível explicar por que motivo se considera ser válido aderir à norma. Chamar uma norma de "princípio" significa portanto, que ela tanto é relativamente geral como tem valor positivo.14

Alexy esclarece que a argumentação racional é o apelo a universalidade, visa a um ideal de comunidade universal, que pode ser interpretado como uma comunidade em paz, logo as ações argumentativas que passam como elementos de um discurso que busca o consenso e esse pode ser entendido como paz social,

O postulado de abertura ao criticismo e a condição de tolerância são o resultado da natureza provisional de cada resolução. O primeiro, para usar a terminologia de Habermas, se refere à prontidão de começar e conduzir discursos; o segundo se relaciona com as ações. À parte do fato de essas regras governarem o comportamento para com os outros, existe a exigência de que o orador deseje a universalidade, mesmo que bela não possa ser atingida. "A característica da argumentação racional é o apelo à universalidade - um apelo cuja realização nunca é assegurada. Visa-se a "realização do ideal da comunidade universal"(la réalisation de l'ideal de

13 FAORO, Raimundo. Os donos do poder: formação do patronato político brasileiro. Porto Alegre: Globo; São Paulo: Editora Universidade de São Paulo, 1975.

${ }^{14}$ MACCORMICK, Neil. Argumentação Jurídica Teoria do Direito. São Paulo: Martins Fontes, 2006. p. $197-$ 198.

Rev. de Teorias da Just., da Decisão e da Argumentação Jurídica | e-ISSN: $2525-9644$ | Brasília | v. 3 | n. 1 | p. $1-19$ | Jan/Jun. 2017. 
communion universelle). A relação dessa communion universelle com a situação de discurso ideal de Habermas é inegável.15

Em busca da lógica do discurso e em consequência da lógica da argumentação jurídica Alexy, lança mão do conceito de força do melhor argumento, para tentar explicar a questão do consenso e como esse se estabelece.

O significado de verdade não está no fato de que algum consenso seja de fato atingido, mas antes nisto: que a qualquer hora e em qualquer lugar em que entrarmos num discurso, podemos alcançar um consenso sob certas condições que provem que se trata de um consenso bem fundamentado. Um consenso bem fundamentado só é um consenso quando se baseia "na força do argumento melhor". Mas o que torna um argumento melhor do que outro, e em que consiste a força do melhor argumento? Habermas resolve esclarecer esta questão no contexto de uma lógica do discurso. O tema de uma lógica do discurso é a característica formal dos vínculos entre os passos de um argumento. Decisivo é que esse encadeamento de passos num argumento não consiste de sentenças, mas de atos de discurso. Portanto, a lógica do discurso tem de ser uma lógica pragmática. No centro da lógica do discurso está o argumento. "Um argumento é a justificação, que nos deve motivar, a reconhecer a condição de validade implícita numa afirmação ou uma ordem, respectivamente uma avaliação.16

\subsection{O QUE É ARGUMENTAÇÃO JURÍDICA?}

O segundo ponto a ser analisado é conceito de argumentação jurídica. Verifica-se nos escritos de Claudia Toledo uma definição de teoria da argumentação jurídica que a aproxima da teoria do discurso,

A teoria da argumentação jurídica relaciona-se diretamente com a teoria do discurso. Visa a questionar e demonstrar a possibilidade e a validade de uma fundamentação racional do discurso, especificamente jurídico, estipulandolhe algumas regras e formas. Situa-se, portanto, no contexto da Filosofia do séc. XX, pós-reviravolta lingüístico-pragmática.17

Sendo assim, a argumentação jurídica se liga de com a teoria do discurso, mas dessa diferencia-se quando a raiz da argumentação jurídica está em regras e formas com baseadas na lei e em princípios do direito.

Ainda segundo Claudia Toledo a importância da argumentação jurídica se sustenta na necessidade da justificação racional das decisões jurídicas,

A possibilidade de justificação racional do discurso jurídico é questão de primacial relevância para a cientificidade do Direito, a qual é imprescindível para a solidez de um Estado Democrático de Direito. Apenas se caracterizam como consensos racionais (e, dentro deles, o jurídico), aqueles passíveis de uma justificação discursiva segundo regras de argumentação. 18

Dessa forma, de acordo com o pensamento de Claudia Toledo a possibilidade de justificação das decisões é de suma importância para a solidez do Estado Democrático de Direito. Quando se justifica as decisões de forma racional termina-se evitando o arbítrio e a

\footnotetext{
15 ALEXY, Robert. Teoria da argumentação Jurídica. 3. ed. São Paulo: Landy, 2001. p. 140.

16 Ibidem, p. 99.

17 TOLEDO, Cláudia. Teoria da Argumentação Jurídica. Revista da Escola Superior Dom Helder Câmara Veredas do Direito. v. 2, n. 3 - jan. dez. - 2005.

18 Ibidem.
}

Rev. de Teorias da Just., da Decisão e da Argumentação Jurídica l e-ISSN: $2525-9644$ | Brasília|v. $3|\mathrm{n} .1| \mathrm{p} .1-19 \mid \mathrm{Jan} / \mathrm{Jun} .2017$. 
discricionariedade. Essa é uma das bases para a teoria da argumentação jurídica em Atienza é acreditar que quanto mais justa uma decisão, mais lógica será a decisão.

\subsection{ARGUMENTAÇÃO JURÍDICA E HERMENÊUTICA JURÍDICA}

A argumetação jurídica e a hermenêutica são métodos distintos de explicação de decisões judiciais. No entanto, em alguns pontos esses métodos convergem e em outros não. O importante é não confundir as duas. No intento diferenciá-las é interessante verificar o conceito dado de hermenêutica por Luís Roberto Barroso e logo após para a questão da argumentação nos órgãos judiciais que tem uma função inegavelmente política.

A hermenêutica jurídica é um domínio técnico especulativo, voltado para a identificação, desenvolvimento e sistematização dos princípios de interpretação do Direito. A interpretação jurídica consiste na atividade de revelar ou atribuir sentido a textos ou outros elementos normativos (como princípios implícitos, costumes, precedentes), notadamente para o fim de solucionar problemas. Tratar-se de uma atividade intelectual informada por métodos, técnicas e parâmetros que procuram dar a ela legitimidade, racionalidade e controlabilidade. 19

Para o Ministro Barroso a hermenêutica se preocupa com a legitimidade, racionalidade e controlabilidade das decisões judiciais. Ainda na concepção de Barroso, referente à argumentação nos órgãos do judiciário tem-se,

Os métodos de atuação e de argumentação dos órgãos judiciais são, como se sabe jurídicos, mas a natureza de sua função é inegavelmente política, aspecto que é reforçado pela exemplificação acima. Sem embargo de desempenhar um poder político, o Judiciário tem características diversas das dos outros Poderes. É que seus membros não são investidos por critérios eletivos nem por processos majoritários. E é bom que seja assim. A maior parte dos países do mundo reserva uma parcela de poder para que seja desempenhado por agentes públicos selecionados com base no mérito e no conhecimento específico. Idealmente preservado das paixões políticas, ao juiz cabe decidir com imparcialidade, baseado na Constituição e nas leis. Mas o poder de juízes e tribunais, como todo poder em um Estado democrático, é representativo. Vale dizer: é exercido em nome do povo e deve ser contas à sociedade. 20

Para Barroso a função da argumentação no judiciário é exercer um papel político e sendo assim, voltado ao convencimento do povo, porque a esse deve prestar contas. Um aspecto que se destaca no trecho é a questão do Poder Judiciário estar constantemente preocupado com sua legitimidade (ethos), pois seus membros não são eleitos. Um dos fatores que se agarra o judiciário para suprir essa lacuna de legitimidade, é que as decisões proferidas têm a expectativa da aceitação popular e que o povo entenda que aquilo que foi decidido é o mais justo. Isso reflete não só uma busca por legitimidade, mas uma busca pelo convencimento e mais uma vez percebe-se como a retórica faz parte do discurso jurídico. Nesse sentido, não pode deixar de confirmar o que foi explicado até aqui, com um excerto de Luhmann, que segundo esse autor as decisões proferidas têm a expectativa de aceitação

19 BARROSO, Luis Roberto. In: Interpretação Constitucional como Interpretação Específica. In: CANOTILHO, J. J. Gomes; MENDES, Gilmar F. ; SARLET, Ingo W. ; STRECK, Lenio L.(Coords.). Comentários à Constituição do Brasil. São Paulo: Saraiva/Almedina, 2013. p. 91.

20 BARROSO, Luís Roberto. Curso de direito constitucional contemporâneo: os conceitos fundamentais e a construção do novo modelo. 2 ed. São Paulo: Saraiva, 2010.

Rev.de Teorias da Just., da Decisão e da Argumentação Jurídica l e-ISSN: 2525-9644| Brasília|v. 3|n. 1 p. 1-19|Jan/Jun. 2017. 
popular e que a aceitação se reflita na mudança de comportamento e aprendizado da população,

[...] a decisão é legitimada através da expectativa da aceitação. A legitimidade da legalidade é a integração desses dois processos de aprendizado. Ela torna-se instituição, na medida em que possa ser suposto o aprendizado nesse duplo sentido: que processos diferenciados de aprendizado regulem a decisão e a aceitação de decisões sobre a expectativas normativas. 21

No caso da Súmula das Algemas essa decisão teve uma expectativa de aceitação e por isso veio a ser um paradigma na atuação policial e até hoje existem reclamações por parte de policiais e associações para com o uso das algemas.

\subsection{A PERSUASÃO NA ARGUMENTAÇÃ̃O JURÍDICA}

O elemento que mais se destaca na retórica é a questão da persuasão do auditório. A persuasão é o elemento mais polêmico dessa técnica. Visto que, persuadir é convencer o outro e com isso pode-se tentar convencer o auditório a qualquer custo esquecendo, assim, da verdade ou da verossimilhança dos fatos. $\mathrm{O}$ que pode colocar o aplicador da lei em uma situação de promoção da injustiça.

Um dos principais objetivos da retórica sofística sempre foi convencer. Independente dos argumentos utilizados, o objetivo sempre era vencer um debate e para isso precisava-se convencer. Convercer é persuadir alguém. É fazer com que alguém venha ter as convicções do emissor do discurso, usando para tanto, apenas o poder das palavras, o poder de um discurso bem construído.

Em contrapartida, verifica-se na Teoria de Atienza que a maior preocupação que se tem é com a lógica deôntica da justificação da decisão. Para Atienza a decisão quanto mais lógica mais justa, é independente do convencimento, o seu convencimento se daria pela congruência ou por estar de acordo com o sistema jurídico (logos) de um determinado local.

\section{EXPOSIÇÃO DO CASO CONCRETO}

O HC nº. 91.952-9 foi julgado no dia 07 de agosto de 2008, em uma sessão do Tribunal Pleno da Corte, com a presença do então Presidente do Supremo Tribunal Federal, Ministro Gilmar Mendes, e tendo como Ministro Relator: Min. Marco Aurélio. Além desses já citados, participaram do julgamento em ordem de votação: Ministro Menezes Direito, Ministra Cármen Lúcia, Mininstro Ricardo Lewandowski, Ministro Eros Grau, Ministro Joaquim Barbosa, Ministro Carlos Ayres Britto, Ministro Cezar Peluso e a Ministra Ellen Gracie. O Ministro Gilmar Mendes votou por último por ser uma matéria com feição constitucional. Não estava presente na sessão o Ministro Celso de Mello.

\subsection{O RELATÓRIO PROCESSUAL DO HABEAS CORPUS 91.952-9 SÃO PAULO}

Para uma melhor exposição do caso concreto a ser analisado, optou-se iniciar a exposição do caso, ${ }^{22}$ a partir de um resumo do relatório processual. Para assim, poder-se ter uma ideia de como se deu os fatos a serem discutidos na sessão plenária.

21 LUHMANN, Niklas. Sociologia do direito. v. 1, Rio de Janeiro: Tempo Brasileiro, 1983.

22 BRASIL. Supremo Tribunal Federal. Habeas Corpus. ALGEMAS - UTILIZAÇÃO. O uso de algemas surge excepcional somente restando justificado ante a periculosidade do agente ou risco concreto de fuga. JULGAMENTO - ACUSADO ALGEMADO - TRIBUNAL DO JÚRI. Implica prejuízo à defesa a manutenção do réu algemado na sessão de julgamento do Tribunal do Júri, resultando o fato na insubsistência 
Segundo o relatório do caso, consta do processo que o paciente foi denunciado como incurso nos artigos $121, \S 2^{\circ}$, incisos II - motivo fútil III - meio cruel - e IV - mediante recurso que impossibilitou a defesa da vítima. Foi recebida a denúncia oferecida pelo Ministério Público, em que lhe imputada infração ao artigo 10 da Lei $n^{\circ}$ 9.437/97, em virtude de possuir, portar e manter arma de fogo, de uso permitido, sem autorização e em desacordo com determinação legal ou regulamentar.

O réu foi pronunciado. Desprovido o recurso em sentido estrito interposto contra a decisão foi submetido a julgamento pelo Tribunal do Júri, sendo condenado à pena de treze anos e seis meses de reclusão, por infração ao artigo 121, § 2a, incisos II, III e IV, do Código Penal e à pena de um ano de detenção e dez dias-multa, como incurso no artigo $10 \mathrm{da}$ Lei $\mathrm{n}^{\mathrm{o}}$ 9.437/97, observado o disposto no artigo 69 do Código Penal. A defesa interpôs recurso de apelação, arguindo preliminares de nulidade do julgamento: a) por erro de votação do terceiro quesito; b) em virtude do fato de o réu ter permanecido algemado durante a assentada em que realizado o júri; c) porque indeferidos, pelo Juiz togado, quesitos pertinentes à absorção do delito de porte de arma pelo de homicídio. No mérito, pleiteou o reconhecimento da legítima defesa, da inexigibilidade de conduta diversa, do estado de violenta emoção após injusta provocação da vítima. A Procuradoria Geral da República, em parecer entede que não afronta o princípio da presunção de não culpabilidade, a manutenção do réu algemado durante a sessão plenária do Tribunal do Júri não configura constrangimento ilegal se a medida se mostra necessária ao bom andamento do julgamento e à segurança das pessoas que nele intervêm. A adoção do procedimento ficaria a critério do Juiz-Presidente do Tribunal do Júri no exercício da polícia das sessões.

Passa-se a análise do caso com o voto do Ministro Relator Marco Aurélio, que levanta uma série de institutos legais que merecem ser analisados para que se possa entender e compor a representação gráfica adequada dos votos do Ministro Relator, juntamente com as contribuições dos outros Ministros do STF.

\subsection{O VOTO DO MINISTRO RELATOR MARCO AURÉLIO}

Para se dar um enfoque mais didático na análise dos votos, detecta-se que o Ministro Relator usa 4 (quatro) tipos de fundamentação para seu voto: a primeira fundamentação baseada na Constituição; a segunda fundamentação está baseada em precedentes juridícos; uma terceira fundamentação baseada em legislação histórica; e na quarta fundamentação com fulcro na legislação análoga. Partindo para um análise quantitativa do voto, contabiliza-se um total de: 11 fundamentos constitucionais, 4 precedentes baseados na jurisprudência, 6 precedentes históricos, e 1 legislação análoga.

Agora passa-se a exposição de todos os fundamentos utilizados no voto do Ministro Relator.

1) Quanto aos fundamentos constitucionais que foram utilizados:

Os art. $1^{\circ}$, III, da Constituição Federal de $1988,{ }^{23}$ relacionado a dignidade da pessoa humana e a proteção dos direito fundamentais estatuídos no art. 5º III, X, XLVIII, XLIX, LVII, LXI, LXII, LXIII, LXIV, LXV, LXVI, LXVIII da Constituição Federal de $1988 .{ }^{24}$

do veredicto condenatório. HC 91.952-9/SP. Tribunal Pleno. Paciente: ANTONIO SÉRGIO DA SILVA. COATOR(A/S) (ES): SUPERIOR TRIBUNAL DE JUSTIÇA. Relator(a): Min. Marco Aurélio. Brasília, 07, de agosto de 2008. Disponível em: <http://redir.stf.jus.br/paginadorpub/paginador.jsp?docTP=AC\&docID=5 70157>. Acesso em: 13 ago. 2013.

23 BRASIL. Constituição 1988. Constituição da República Federativa do Brasil de 1988. 1988. Disponível em: <http://www.planalto.gov.br/ccivil_03/constituicao/constituicao.htm>. Acesso em: 29 nov. 2013. 
2) Fundamentos legais históricos:

O Código de Processo Criminal do Império - de 29 de novembro de 1832 -, no capítulo "Da Ordem de Prisão", dispunha, no artigo 180, que, "se o réu não obedecer e procurar evadir-se, o executor tem direito de empregar o grau da força necessária para efetuar a prisão, se obedecer porém, o uso da força é proibido". A Lei no 261, de 3 de dezembro de 1841, reformou o Código de Processo Criminal, mas manteve a mencionada norma. 25

3) Fundamento baseado em precedente internacional:

Vale registrar, ainda, que o item 3 das regras da Organização das Nações Unidas para tratamento de prisioneiros estabelece que o emprego de algemas jamais poderá se dar como medida de punição. Isso indica, à semelhança do que antes previsto no artigo 180 do Código de Processo Criminal do Império, que o uso desse instrumento é excepcional e somente pode ocorrer nos casos em que realmente se mostre indispensável para impedir ou evitar a fuga do preso ou quando se cuidar comprovadamente de perigoso prisioneiro.

4) Fundamento legal infraconstitucional:

O art. 350 do Código Penal brasileiro. ${ }^{26}$ Os arts. 284 e 474, § 30 do Código de Processo Penal. ${ }^{27}$ Ainda nesse mesmo sentido o art. 234, $\S 1^{\circ}$ do Código de Processo Penal Militar $^{28}$, e por último o art. $4^{\circ}$, "a" Lei 4898/196529, que trata sobre o abuso de autoridade.

5) Fundamentos baseados em precedentes do próprio STF:

RHC 56.465 com publicação no Diário da Justiça em Publicação no Diário da Justiça de 6/10/1978. HC 71.195-2/SP com publicação no Diário da Justiça em publicação no dia 4/8/1995. HC 89.429-1/RO com publicação no Diário da Justiça em 2/2/2007, HC 91952 com publicação no Diário da Justiça Eletrônico n ${ }^{\circ} 241$ no dia 19/12/2008. ${ }^{30}$

24 BRASIL. Constituição 1988. Constituição da República Federativa do Brasil de 1988. 1988. Disponível em: <http://www.planalto.gov.br/ccivil_03/constituicao/constituicao.htm>. Acesso em: 29 nov. 2013.

25 BRASIL. Supremo Tribunal Federal. Habeas Corpus. ALGEMAS - UTILIZAÇÃO. O uso de algemas surge excepcional somente restando justificado ante a periculosidade do agente ou risco concreto de fuga. JULGAMENTO - ACUSADO ALGEMADO - TRIBUNAL DO JÚRI. Implica prejuízo à defesa a manutenção do réu algemado na sessão de julgamento do Tribunal do Júri, resultando o fato na insubsistência do veredicto condenatório. HC 91.952-9/SP. Tribunal Pleno. Paciente: ANTONIO SÉRGIO DA SILVA. COATOR(A/S) (ES): SUPERIOR TRIBUNAL DE JUSTIÇA. Relator(a): Min. Marco Aurélio. Brasília, 07, de agosto de 2008. Disponível em: <http://redir.stf.jus.br/paginadorpub/paginador.jsp?docTP=AC\&docID=5 70157>. Acesso em: 13 ago. 2013.

26 BRASIL. Decreto-Lei $n^{\circ}$ 2.848. Código Penal. 1940. Disponível em: < http://www.planalto.gov.br/ ccivil_03/decreto-lei/del2848compilado.htm >. Acesso em: 29 nov. 2013.

27 BRASIL. Lei $n^{\circ}$ 4.868, de 09 de dezembro de 1965. Regula o Direito de Representação e o processo de Responsabilidade Administrativa Civil e Penal, nos casos de abuso de autoridade. 1965. Disponível em: < http://www.planalto.gov.br/ccivil_03/leis/14898.htm>. Acesso em: 29 nov. 2013.

28 BRASIL. Decreto-Lei $n^{o}$ 1.002, de 21 de outubro de 1969. Código de Processo Penal Militar. 1969. Disponível em: < http://www.planalto.gov.br/ccivil_03/decreto-lei/del1002.htm >. Acesso em: 29 nov. 2013.

29 BRASIL. Lei $n^{\circ}$ 4.868, de 09 de dezembro de 1965. Regula o Direito de Representação e o processo de Responsabilidade Administrativa Civil e Penal, nos casos de abuso de autoridade. 1965. Disponível em: < http://www.planalto.gov.br/ccivil_03/leis/14898.htm>. Acesso em: 29 nov. 2013.

${ }^{30}$ BRASIL. Supremo Tribunal Federal. Habeas Corpus. ALGEMAS - UTILIZAÇÃO. O uso de algemas surge excepcional somente restando justificado ante a periculosidade do agente ou risco concreto de fuga. JULGAMENTO - ACUSADO ALGEMADO - TRIBUNAL DO JÚRI. Implica prejuízo à defesa a manutenção do réu algemado na sessão de julgamento do Tribunal do Júri, resultando o fato na insubsistência

Rev.de Teorias da Just., da Decisão e da Argumentação Jurídica l e-ISSN: 2525-9644| Brasília|v. 3|n. 1 | p. 1-19|Jan/Jun. 2017. 


\subsection{VOTO DO MINISTRO MENEZES DIREITO}

Voto do Ministro Menezes Direito acompanha o voto do Ministro Relator e não acrescenta nenhum novo elemento de fundamentação.

\subsection{VOTO DA MINISTRA CÁRMEN LÚCIA}

Voto da Ministra Cármen Lúcia cita o Habeas Corpus n. 71.115, que teve como Relator o Ministro Francisco Rezek, durante o voto da Ministra, o Ministro Relator cita que fez consulta a dois magistrados aposentados com ampla experiência no Tribunal do Júri no Estado do Rio de Janeiro e esses magistrados afirmaram que nunca nos anos de suas atividades tiveram que algemar nenhum acusado durante a sessão de julgamento do Tribunal do Júri. Ministro Cezar Peluso também afirma nessa ocasião que quando era presidente do tribunal do júri também nunca teve que manter um acusado de crime doloso contra a vida algemado perante juízes leigos. (p. 3 - voto Ministra Carmem Lúcia)

\subsection{VOTO DO MINISTRO RICARDO LEWANDOWSKI}

Em seu voto, o Ministro Ricardo Lewandowski cita o artigo 497, I, do Código de Processo Penal e sua alteração feita pela Lei n. 11.689/2008, que define parâmetros a serem obedecidos e o art. 474, $\S 3^{\circ}$. do Código de Processo Penal.

\subsection{VOTO DO MINISTRO EROS GRAU}

No voto do Ministro Eros Grau trás para seu voto um trecho do Professor Sérgio Marques de Moraes Pitombo, que considera aviltante e tortura o uso de algemas.

"Aflora intuitivo que o abuso de algemas se constitui em prática atroz, bestial ou aviltante, podendo chegar à tortura. Tal desvio de conduta, antes de tudo, viola o inarredável acatamento à integridade física e psíquica do preso, ou do conduzido, por isso mesmo será crime."

Também nesse mesmo sentido considera abuso de autoridade o uso desnecessário de algemas. E assim, cita a Lei n. 4.898, artigo 4, alínea "b".

\subsection{VOTO DO MINISTRO JOAQUIM BARBOSA}

Voto do Ministro Joaquim Barbosa trás a questão da gravidade do fato ocorrido por justa causa da necessidade de fundamentação do juiz leigo ao julgar uma pessoa, no processo do tribunal do Júri. Volta a questão do Art. 474, $\S 3^{\circ}$, do CPP. Além disso, o Ministro Joaquim Barbosa fornece parâmetros para fundamentar possíveis novos casos onde exista a necessidade de algemar perante do Tribunal do Júri. Como regra pode-se o réu deve ficar sem algemas.

1) Eventual periculosidade do paciente.

2) Histórico de violência no convívio social ou na prisão.

3) Qualquer outro dado concreto que fundamente o temor do juiz presidente do Tribunal do Júri.

E o Ministro conclui que se não for demonstrada essa periculosidade há constrangimento contra o acusado.

\subsection{VOTO DO MINISTRO CARLOS AYRES BRITTO}

No voto do Ministro Carlos Ayres Britto retoma a questão constitucional do Art. $5^{\circ}$., III. - ninguém será submetido a tortura nem a tratamento desumano ou degradante. Além disso durante o voto assevera que "é sabido que as algemas constrangem fisicamente,

do veredicto condenatório. HC 91.952-9/SP. Tribunal Pleno. Paciente: ANTONIO SÉRGIO DA SILVA. COATOR(A/S) (ES): SUPERIOR TRIBUNAL DE JUSTIÇA. Relator(a): Min. Marco Aurélio. Brasília, 07, de agosto de 2008. Disponível em: <http://redir.stf.jus.br/paginadorpub/paginador.jsp?docTP=AC\&docID=5 70157>. Acesso em: 13 ago. 2013. 
psicologicamente, abatem senão a moral o moral do preso, do algemado, e evidente que o seu uso desnecessário viola o inciso III, do Art. $5^{\circ}$. CF..."

Ministro Carlos Ayres Britto também cita a Extradição no. 1.122, assim como a Extradição 1.087 onde expediu o mandado de prisão, de captura, a ser cumprido pelo Departamento de Polícia Federal, mas dizendo que...

\subsection{VOTO DO MINISTRO CEZAR PELUSO}

O Ministro Cezar Peluso prolata outro voto relativamente extenso nesse julgado, onde abarca uma série de argumentos complementares e no mesmo sentido do voto do Ministro Marco Aurélio. Basicamente os fundamentos dos votos estão em iguai ditames do voto do Ministro Marcos Aurélio. Sejam: 1) Fundamentos legais históricos; 2) Fundamentos baseado em precedentes internacionais; e 3) Fundamento baseados na doutrina.

\subsection{VOTO DA MINISTRA ELLEN GRACIE}

O voto da Ministra Ellen Gracie acompanha o voto do Ministro Relator Marco Aurélio e não acrescenta nenhum novo elemento de fundamentação.

\subsection{VOTO MINISTRO PRESIDENTE DO STF GILMAR MENDES}

Voto do Ministro Presidente do STF Gilmar Mendes acompanha o voto do Ministro Marco Aurélio. O voto recorda uma interpretação do Professor Sérgio Pitombo ${ }^{31}$ em relação ao Art.153, § 14 da Constituição da Emenda n. 1 de 1969, trazendo dessa forma, mais um elemento doutrinário.

"As algemas podem também servir para só insultar ou castigar - tortura psíquica, consistente na injusta vexação, e física, no aplicar a sanção imprevista -, dar tratamento, enfim, degradante, desumano ao que se acha sob a guarda ou em custódia, violando a garantia individual (\$14 do art. 153 da Constituição da Emenda no 1/69)".

Por fim o resultado que foi a construção jurisprudencial em torno do texto da Súmula Vinculante $\mathrm{n}^{\circ} .11$,

"Só é lícito o uso de algemas em caso de resistência e de fundado receio de fuga ou de perigo à integridade física própria ou alheia, por parte do preso ou de terceiros, justificada a excepcionalidade por escrito, sob pena de responsabilidade disciplinar civil e penal do agente ou da autoridade e de nulidade da prisão ou do ato processual a que se refere, sem prejuízo da responsabilidade civil do Estado".

\subsection{A REPRESENTAÇÃO DOS VOTOS SEGUNDO O MODELO DE ATIENZA}

Um dos pontos de crítica de Atienza a outros autores que se encaixam na teorias padrão da argumentação jurídica é a ausência de um modo de representação da argumentação de forma gráfica. Para suprir essa lacuna Atienza cria um conjunto gráfico capaz de representar o sentido, significado e o pragmatismo da argumentação jurídica.

$\mathrm{Na}$ minha opinião, um dos maiores defeitos da teoria padrão da argumentação jurídica é precisamente o fato de ela não ter elaborado um procedimento capaz de representar adequamento como os juristas fundamentem, de fato, as suas decisões. Tanto MacCormick quanto Alexy recorrem, para isso à lógica formal dedutiva - digamos, à lógica clássica -,

31 PITOMBO, Sérgio Marcos de Moraes. Emprego de algemas - notas em prol de sua regulamentação. Revista dos Tribunais, São Paulo, v. 592, p. 275-292, fev. 1985, p. 275.

Rev.de Teorias da Just., da Decisão e da Argumentação Jurídica l e-ISSN: $2525-9644$ | Brasília|v. 3| n. 1 | p. 1-19|Jan/Jun. 2017. 
mas me parece que esta, por si só, não é um instrumento suficiente para cumprir esse objetivo. Basicamente porque nos processos de argumentação jurídica - assim como na argumentação da vida comum - têm um papel fundamental as relações de "ser um argumento a favor de " e "ser um argumento contra", que não podem ser traduzidas adequadamente em termos da noção habitual de inferência lógica: $x$ pode ser um argumento a favor de y e ser verdadeiro(ou em geral, válido), o que não impede y de ser falso, porque, por exemplo, z é um argumento contra y com peso maior que x. Por outro lado o processo de argumentação não é, por assim dizer, linear, mas antes reticular; seu aspecto não lembra uma cadeia, e sim a trama de um tecido. Um fragmento de argumentação jurídica poderia, na minha opinião, ser adequadamente representado se se utilizam diagramas que permitam dar conta tanto do aspecto sintático, quanto do aspecto semântico e pragmático da argumentação. Assim, em primeiro lugar é preciso representar as relações existente entre os argumentos". 32

Para verificar o aspecto sintático Atienza utiliza de cinco relações básicas:

1) argumentos a favor de;

2) argumentos contra;

3) argumentos que conjuntamente constituem a favor de outro;

4) argumentos que independentemente constituem argumento a favor de outro;

5) um primeiro argumento ajuda a fundamentar um terceiro com ajuda do segundo.

Quanto a parte semântica da argumentação, Atienza acredita que cada um dos argumentos deve ser isolado e representado cada um através das letras, exemplo, $\boldsymbol{a}, \boldsymbol{b}, \boldsymbol{c}^{33} \mathrm{e}$ quantas outras sejam necessárias para a representação.

Dessa forma, elenca-se cinco maneiras básicas de representar essas relações entre os argumentos. Conforme o conjunto de representações reproduzidas em seguida, essas tentam reproduzir os aspectos sintáticos e semânticos da argumentação jurídica de modo conjunto $^{34}$.

Figura 1 - Representação de relações entre os argumentos.

1) $\boldsymbol{a}$ um argumento independente e a favor de $\boldsymbol{b}$;

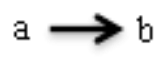

2) $\boldsymbol{a}$ é um argumento independente e contra $\mathbf{b}$;

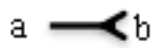

3) $\boldsymbol{a}$ e b conjuntamente, constituem um argumento a favor de $\mathbf{c}$;

ATIENZA, Manuel. As razões do direito: teorias da argumentação jurídica. 3. ed. São Paulo: Landy, 2003. p.216.

Para as representações ficarem didáticas os argumentos usados serão colocados em forma de letras negritadas e em itálico, para que dessa forma se gere um destaque para não confundir o leitor.

4 ATIENZA, Manuel. As razões do direito: teorias da argumentação jurídica. 3. ed. São Paulo: Landy, 2003. p. 216 .

Rev.de Teorias da Just., da Decisão e da Argumentação Jurídical e-ISSN: $2525-9644$ | Brasília|v. 3|n. 1 | p. 1-19|Jan/Jun. 2017. 


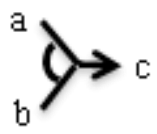

4) $\boldsymbol{a}$ e b (cada um isoladamente), constituem um argumento a favor de $\boldsymbol{c}$;

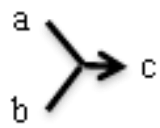

5) $\boldsymbol{a}$ é um argumento para fundamentar $\mathbf{c}$ com a ajuda de $\mathbf{b}$.

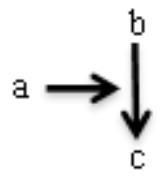

Fonte: ATIENZA, Manuel. As razões do direito: teorias da argumentação jurídica. 3. ed. São Paulo: Landy, 2003. p.216.

Essa série de explicações em um primeiro momento pode ser confusa, mas depois verifica-se quando se visualiza o esquema montado de forma gráfica, que existe uma função e uma necessidade a ser preenchida em cada um deles. ${ }^{35}$

Quanto ao aspecto pragmático, o autor estudado utiliza de figuras geométricas para representar cada ato de linguagem efetuado. Atienza entende, ato de linguagem como sendo um problema proposto, uma afirmação, um enunciado normativo, uma pergunta. Nesse ponto o modelo de Atienza se assemelha com os modelos computacionais de representação de processos. O autor dessa vez elenca sete figuras geométricas para a tarefa ${ }^{36}$.

Figura 2 - Representação semântica argumentos.

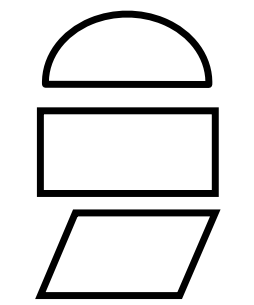

Proposição de um problema;

Afirmação de um enunciado empírico (universal ou singular);

Adoção de um enunciado normativo que obriga, proíbe ou permite fazer algo;

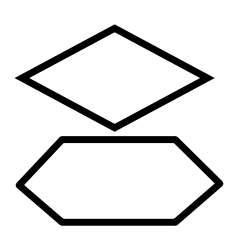

Formulação de uma pergunta que pode ser feita no curso da argumentação e que pode ter uma ou mais saídas;

Assunção de um juízo de valor;

35 Esse trecho é baseado nas explicações do próprio Atienza na página 301 do livro. Essa forma foi uma maneira mais didática que foi encontrada para fazer a representação dos argumentos.

6 ATIENZA, Manuel. As razões do direito: teorias da argumentação jurídica. 3. ed. São Paulo: Landy, 2003. p.18.

Rev. de Teorias da Just., da Decisão e da Argumentação Jurídica l e-ISSN: $2525-9644$ | Brasília | v. 3 | n. 1 | p. 1 - 19 | Jan/Jun. 2017 


\section{$\sum$ Estabelecimento de uma definição ou de um postulado de significado;}

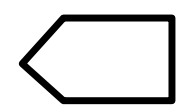

Adoção de um princípio (que pode ser considerado algo a meio caminho entre um valor e uma norma); etc.

Exposição da solução do problema ${ }^{37}$;

Fonte: ATIENZA, Manuel. As razões do direito: teorias da argumentação jurídica. 3. ed. São Paulo: Landy, 2003. p.217.

Seguindo a proposta de Atienza para investigar o argumentos e fazer a devida representação gráfica, segue uma série de perguntas que se respondidas de maneira adequada pode-se fazer com uma certa facilidade o diagrama representativo dos votos. Para o item (a) qual o problema a ser resolvido no Habeas Corpus? A reposta seria: Um preso provisório pode ficar algemado em uma sessão do tribunal do júri? Para o item (b) existe realmente uma solução para o problea? A resposta seria: somente a edição de uma súmula vinculante pode por fim aos entendimentos esparços sobre o uso das algemas, visto que a legislação que regularia o uso das algemas ainda não foi votada. Para o item (c), existe uma afirmação de um enunciado empírico (universal ou singular)? Sim, no caso o Art. $474 \S 3^{\circ}$, do Código de Processo Penal. 38 Para o item (d), existe a formulação de uma pergunta que pode ser feita no curso da argumentação e que pode ter uma ou mais saídas. Qual a norma aplicável ao caso? Resposta: não exite uma norma diretamente aplicada ao caso. Por isso o Ministro Marco Aurélio faz uma busca pela Contituição e na legislação infraconstitucional pertinente com vista a tecer uma saída para o caso. Para o item (e), existe a adoção de um enunciado normativo que obriga, proíbe ou permite fazer algo? Sim, como já visto anteriormente com a fundamentação do voto do Ministro Marco Aurélio, existem diversos enunciados normativos que proíbem atitudes que visam constranger o preso. Para o item (h), existe a assunção de um juízo de valor? Resposta: sim, a aplicação de todos os princípios constitucionais elencados pelo Ministro Marco Aurélio. Para o item (g) Existe o estabelecimento de uma definição ou de um postulado de significado? Resposta: sim, ao preso ficar algemado durante um julgamento diante se juízes leigos confere a esse, que continuar almegado diante do Tribunal do Júri composto por juízes leigos, um ônus de culpabilidade e periculosidade sobre a pessoa julgada. Para o item (i) o preso do caso analisa já se encontrava preso e já estava em uma relação se sujeição para com o Poder Judiciário. Para o item (j) verifica-se que nos caso dos presos seus direitos fundamentais já estão limitados. Para o item (l) existe a adoção de um princípio? Resposta: sim, como já visto anteriormente na fundamentação do voto do Ministro Maro Aurélio, existem diversos princípios que proíbem atitudes que visam constranger o preso, mas o principal seria o princípio da Dignidade da Pessoa Humana.

O diagrama proposto para investigação do problema fica assim desenhado.

37 Esse último diagrama não esta representado diretamente entre os diagramas de Atieza, mas se encontra como fechamento dos problemas ou soluções encontradas, de forma didática opta-se por informar esse diagrama.

38 Art. 474. A seguir será o acusado interrogado, se estiver presente, na forma estabelecida no Capítulo III do Título VII do Livro I deste Código, com as alterações introduzidas nesta Seção. [...] § 3o Não se permitirá o uso de algemas no acusado durante o período em que permanecer no plenário do júri, salvo se absolutamente necessário à ordem dos trabalhos, à segurança das testemunhas ou à garantia da integridade física dos presentes." 
Figura 3 - Diagrama representativo dos votos no HC n. 91.952/SP.

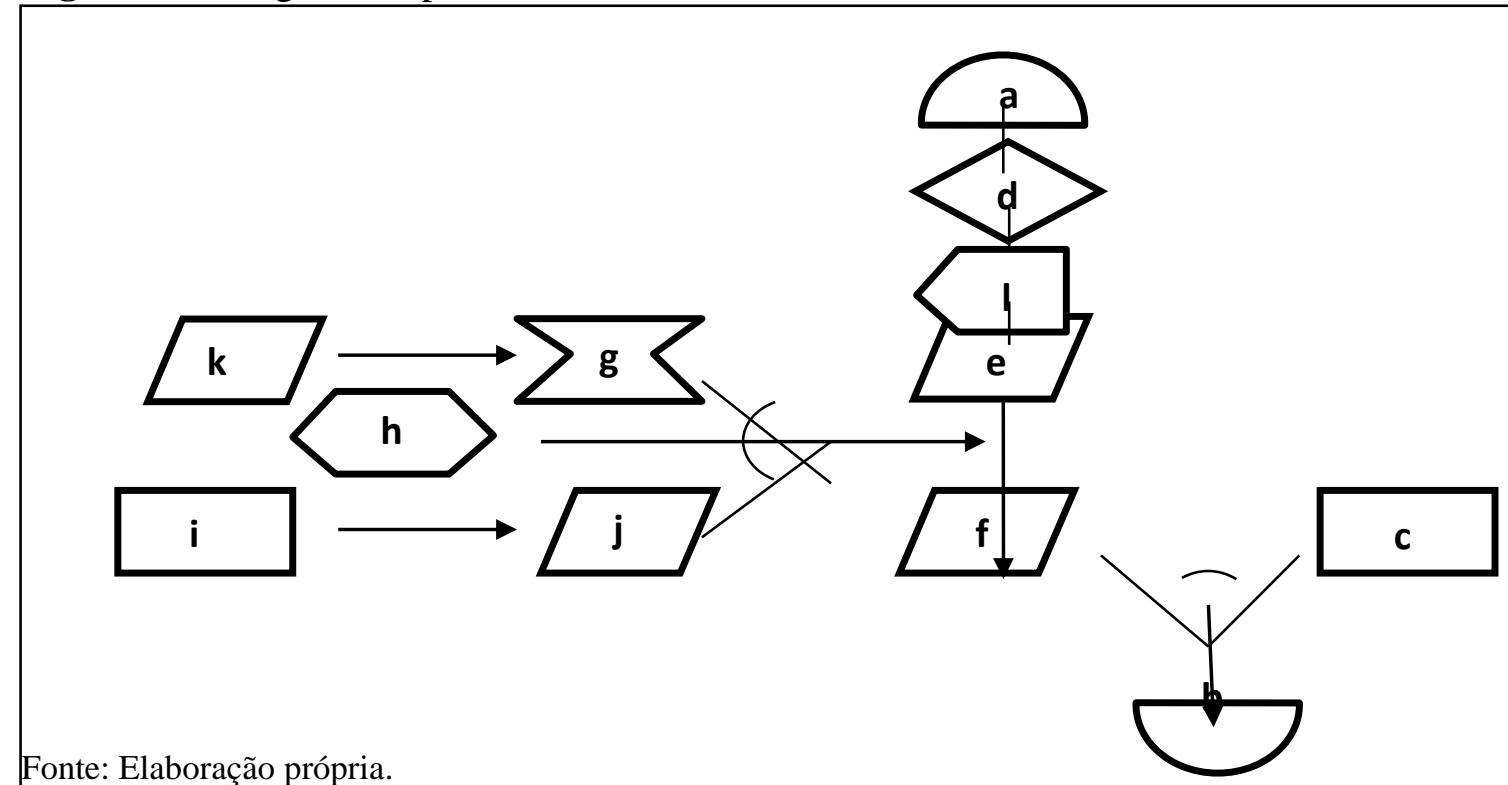

\section{CONCLUSÃO}

Percebe-se que a argumentação jurídica, a retórica, a hermenêutica e outras matérias relacionadas com a filosofia do direito são pouco estudadas nos cursos de graduação em direito. Nos dias atuais, o processo de aprendizados nas faculdades de direito em muito se assemelha com o processo de aprendizado dos cursos preparatórios para concursos. Existe um foco exagerado no tecnicismo do direito, deixando de lado e para poucos uma reflexão mais profunda sobre os temas mais complexos de ordem filosófica. ${ }^{39}$

Mas essas matérias poderiam ou deveriam ser melhor exploradas na graduação, até mesmo porque segundo Atienza, "Um objetivo central do processo de aprendizagem do Direito teria de ser o de aprender a pensar ou raciocinar "como um jurista", não se limitando a conhecer os conteúdos do Direito positivo". ${ }^{40}$ Dessa forma segundo o entendimento de Atienza a argumentação jurídica seria uma base para se entender como um jurista pensa.

Durante as pesquisas para esse artigo foram encontrados outros modelos de análise de decisão como, o da professora Katarina Sobota e do professor Isaac Costa Reis ${ }^{41}$ (Unb) que se baseiam no estudo da retórica. Quando se estuda outros métodos de análise de

39 FREITAS, Vladimir Passos de. Trabalhos acadêmicos e realidade seguem caminhos divergentes. Disponível em: <http://www.conjur.com.br/2014-ago-31/segunda-leitura-divergencias-entre-trabalho-academico-realida de\#author> . Acesso em: 29 de set. 2014.

40 ATIENZA, Manuel. As razões do direito: teorias da argumentação jurídica. 3. ed. São Paulo: Landy, 2003.p. 334.

41 A AERD ou Análise Empírico-Retóricado Discurso Constitucional é metódo de análise do discurso constitucional desenvolvida na tese de doutorado do Professor Doutor Isaac Reis da Univesidade de Brasília. Na AERD se faz uma varredura de todo o voto identificando todas as ocorrências de Pathos, Ethos e Logos. Para depois se contabilizar, e depois transformar em termos percentuais cada um dos elementos. Com isso, pretende-se verificar quais elementos preponderam do discurso, mas não se pretende, através dessa análise ter uma função prescritiva que diga se o voto prolatado é bom ou ruim. REIS, I . Análise Empírico-Retórica do Discurso Constitucional: uma contribuição metodológica para a pesquisa de base em Direito. In: Conpedi/UFSC. (Org.). Direito, Educação, ensino e metodologia jurídicos. 1ed.Florianópolis/SC: CONPEDI, 2014 , v. , p. $70-90$.

Rev.de Teorias da Just., da Decisão e da Argumentação Jurídica l e-ISSN: 2525-9644| Brasília|v. 3|n. 1 p. 1-19|Jan/Jun. 2017. 100 
decisões, percebe-se vários outros caminhos percorridos para o entendimento de uma decisão. De acordo com Aristóteles, todo discurso, acaba tendo 3 elementos, pathos, logos e ethos.

Faz-se notar que nos votos prolatados encontra-se esses elementos elencados por pelo estagirita, os elementos de acordo com o direito posto, outros precedentes do próprio STF, percebe-se a procura de legitimação, a adesão do auditório, os frenquentes elogios.

Atienza cita outros modelos de argumentação jurídica e os crítica pelo excesso de teoria empregado nesses modelos e a falta de uma estudo prático. O modelo de Atienza com certeza é mais didático para iniciar um estudo sobre decisões judiciais, até mesmo por se apegar a questão gráfica e a questão da praticidade de seu uso e a análise relacionado ao elemento do $\log o s$ da decisão.

Para Atienza a decisão mais justa senpre será a mais lógica, mas a conclusão que se chega é que nem sempre a decisão mais justa, será necessariamente a mais lógica (logos) que prepondera sobre outros elementos, ou a decisão estiver mais de acordo com as leis estabelecidas. Uma decisão pode ser justa mesmo que apele para os outros elementos enumerados por Aristóteles como o pathos ou ethos. Talvez a decisão mais justa seja a que alcançar melhor a paz social com menos danos sociais ou econômicos.

O Modelo de Teoria de Argumentação Jurídica de Manuel Atienza como se vê, é bastante útil para a análise dos aspectos lógicos (logos) de uma decisão, é possível mapear os argumentos, mostrá-los graficamente e tentar com isso extrair o sentido e o significado de um determinado julgamento. É possível fazer uma análise bastante objetiva de uma decisão, utilizando parâmetros dedutíveis da própria decisão.

O Modelo se mostra como uma ferramenta de uso relativamente simples, mas trabalhoso, podendo ser usada para se verificar a justeza e vários outros aspectos da fundamentação de uma decisão judicial. Lógico que a ferramenta aqui apresentada não é uma ferramenta suficiente para analisar toda, e qualquer decisão judicial, sobre múltiplos aspectos, mas muitas decisões podem ser analisadas por esse método.

Ressalta-se que a decisão sem um mínimo de lógica deôntica, que é a lógica normativa, fica carente de congruência, ou legitimidade, e até de coerência com o sistema legal. ${ }^{42}$ Mas mesmo assim pode ser perfeitamente justa e suprir uma lacuna do sistema.

Depreende-se das leituras efetuadas que a grande conquista da Teoria de Atienza em detrimento das teorias que a antecederam como a de Alexy e Neil McCormick, foi a questão do desenvolvimento de uma ferramenta gráfica capaz de mapear os argumentos proferidos em uma decisão, e poder através de gráficos, atribuir sentido e significado a decisão analisada. Um ponto mostrado nesse trabalho foi o quão produtivo pode ser esse mapeamento para entender uma decisão judicial, depois que se faz o modelo.

Como já mencionado na introdução o principal problema enfrentado neste trabalho foi a questão, os votos dos Ministros do Supremo Tribunal Federal no HC n.91.9529/SP e se podem ser encaixados no Modelo da Teoria da Argumentação Jurídica de Atienza, de modo a se verificar uma coerência argumentativa e lógica nos votos.

De acordo com o que foi analisado até aqui fica comprovado que os votos dos Ministros obedeceram uma lógica deôntica e argumentativa, e que foi usado pesos e medidas proporcionais para decidir o tema objeto da controvérsia.

Sobre a análise do HC n. 91.952-9/SP juridicamente os votos são irrepreensíveis. Existe uma concentração de acordo com as bases aristotélicas no logos, onde as fundamentações utilizadas estão de acordo com a Constituição de 1988, a legislação pátria, 
os doutrinadores nacionais, internacionais e precedentes internacionais. De acordo com o modelo de Atienza os votos se encaixam no modelo e são "juridicamente bons", porque seguem uma lógica normativa estrita, por isso descarta-se no caso, um tipo de decisionismo do STF.

\section{REFERENCIAS}

ALEXY, Robert. Teoria da argumentação jurídica. 3. ed. São Paulo: Landy, 2001.

ATIENZA, Manuel. As razões do direito: teorias da argumentação jurídica. São Paulo: Landy, 2000.

ATIENZA, Manuel. As razões do direito: teorias da argumentação jurídica. 3. ed. São Paulo: Landy, 2003.

BARROSO, Luís Roberto. STF foi permeável à opinião pública, sem ser subserviente. Revista Consultor Jurídico. 3.1.2012. Disponível em: <http://www.conjur.com.br/2012-jan03/retrospectiva-2011-stf-foi-permeavel-opiniao-publica-subserviente>. Acesso em 20 de Ago. 2013.

BARROSO, Luís Roberto. Curso de direito constitucional contemporâneo: os conceitos fundamentais e a construção do novo modelo. 2 ed. São Paulo: Saraiva, 2010.

BRASIL. A Constituição e o supremo. 2. ed. Brasília: Supremo Tribunal Federal, 2009.

BRASIL. Constituição (1988). Constituição da República Federativa do Brasil. Brasília: Senado Federal, 2005.

BRASIL. Supremo Tribunal Federal. Habeas Corpus. ALGEMAS - UTILIZAÇÃO. O uso de algemas surge excepcional somente restando justificado ante a periculosidade do agente ou risco concreto de fuga. JULGAMENTO - ACUSADO ALGEMADO - TRIBUNAL DO JÚRI. Implica prejuízo à defesa a manutenção do réu algemado na sessão de julgamento do Tribunal do Júri, resultando o fato na insubsistência do veredicto condenatório. HC 91.9529/SP. Tribunal Pleno. Paciente: ANTONIO SÉRGIO DA SILVA. COATOR(A/S) (ES): SUPERIOR TRIBUNAL DE JUSTIÇA. Relator(a): Min. Marco Aurélio. Brasília, 07, de agosto de 2008. Disponível em: <http://redir.stf.jus.br/paginadorpub/paginador.jsp?docTP=A C\&docID=570157>. Acesso em: 13 agosto 2013.

BRETON, Philippe; GAUTHIER, Giller. História das teorias da argumentação. Lisboa: Bizâncio, 2001.

COELHO, Fábio Ulhôa. Roteiro de lógica jurídica. 5. ed. São Paulo: Saraiva, 2004.

COPI, Irving Marmer. Introdução à lógica. Tradução de Álvaro Cabral. 2. ed. São Paulo: Mestre Jou, 1978.

DWORKIN, Ronald. Uma questão de princípios. São Paulo: Martins Fontes, 2000.

DWORKIN, Ronald. Levando os direitos a sério.Tradução de Nelson Boeiras. São Paulo: Martins Fontes, 2002.

HABERMAS, Jürgen. Teoría de la acción comunicativa I: Racionalidad de la acción y racionalización social. Tradução de Manuel Jiménez Redondo. Madrid: Taurus, 1987a.

Teoría de la acción comunicativa II: Crítica de la razón funcionalista. Tradução de Manuel Jiménez Redondo. Madrid: Taurus, 1987b.

Notas programáticas para a fundamentação de uma ética do discurso. In: Consciência Moral e Agir Comunicativo. Tradução de Guido Antônio de Almeida. Rio de Janeiro: Tempo Brasileiro, 1989, pp.61-141.

HAMILTON; MADISON; JAY. O federalista. Belo Horizonte: Líder, 2003.

LUHMANN, Niklas, Sociologia do direito II, Rio de Janeiro: Tempo Brasileiro, 1985.

Rev. de Teorias da Just., da Decisão e da Argumentação Jurídica | e-ISSN: $2525-9644$ | Brasília|v. $3 \mid$ n. 1 | p. $1-19$ | Jan/Jun. 2017. 
MACCORMICK, Neil. Argumentação jurídica teoria do direito. São Paulo: Martins Fontes, 2006.

MENDES, Gilmar Ferreira; COELHO, Inocêncio Mártires; BRANCO, Paulo Gustavo Gonet. Curso de direito constitucional. 4 ed. São Paulo: Saraiva, 2009.

MENDES, Gilmar Ferreira; BRANCO, Paulo Gustavo Gonet. Curso de direito constitucional - Ed.6. São Paulo: Saraiva, 2011.

MONTESQUIEU. Do espírito das leis, São Paulo: Abril Cultural, 1979.

RAMOS, Elival da Silva. Ativismo judicial: Parâmetros dogmáticos. São Paulo: Saraiva, 2010.

REIS, I. Análise Empírico-Retórica do Discurso Constitucional: uma contribuição metodológica para a pesquisa de base em Direito. In: Conpedi/UFSC. (Org.). Direito, Educação, ensino e metodologia jurídicos. 1ed.Florianópolis/SC: CONPEDI, 2014, v. , p. 7090.

SCHOPENHAUER, Arthur. Como vencer um debate sem precisar ter razão: em 38 estratagemas: (Dialética Erística). Rio de Janeiro: Topbooks, 1997. 